\title{
دروس من مسيرة إقبال الإصلاحية
}

\section{هيئة التحرير}

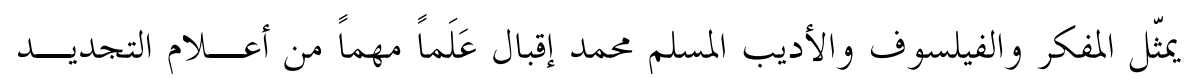

و الإصلاح الفكري الإسلامي الحديث. وغدات نتاجاته الفكرية والفلسفية والأدبية مرجعيات

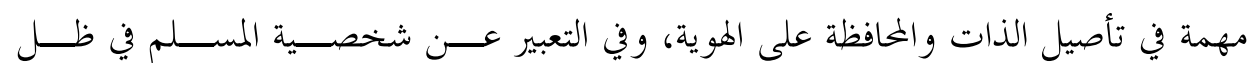

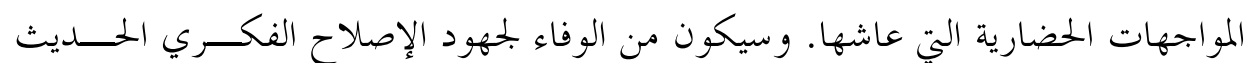

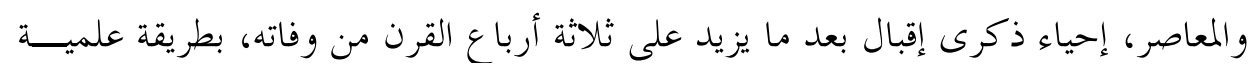

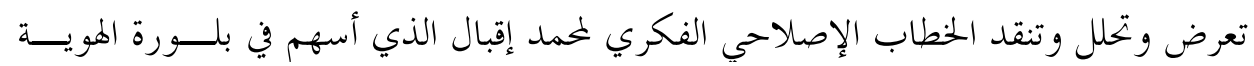

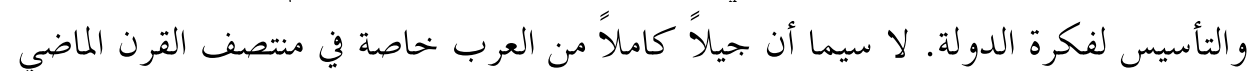

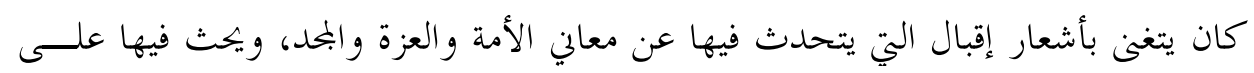
الاعتزاز بالهوية الإسلامية.

إن تفحّص مسيرة إقبال العلمية والعملية تفرض على العاملين في الحقل الفكري و الثقافي

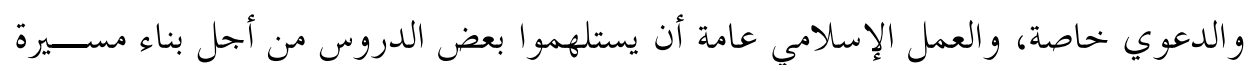

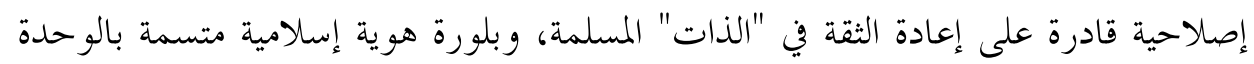

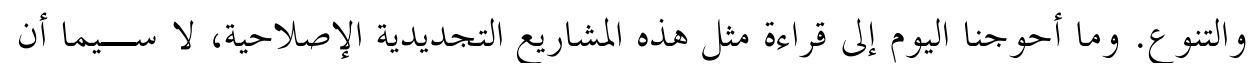

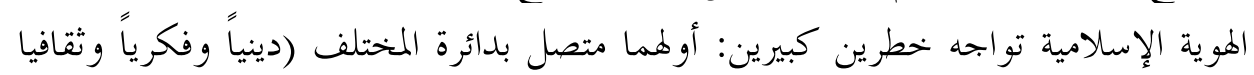

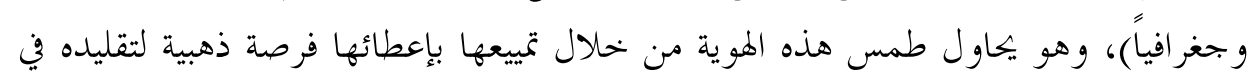

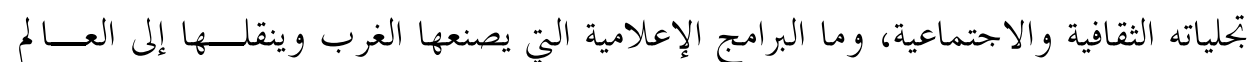

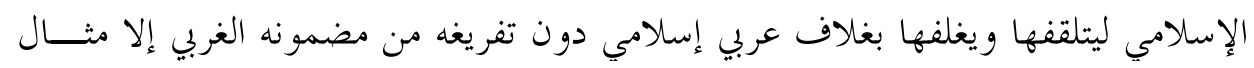

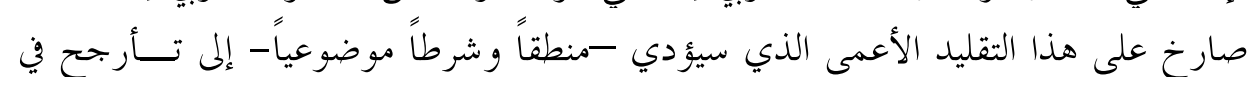

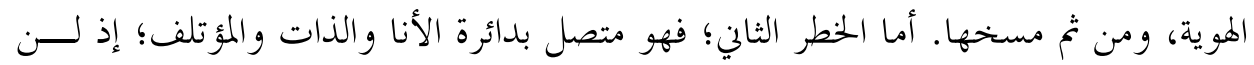

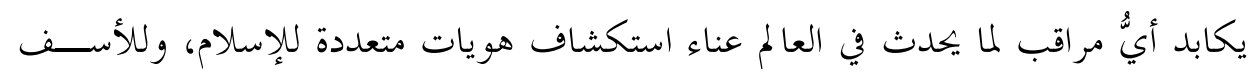

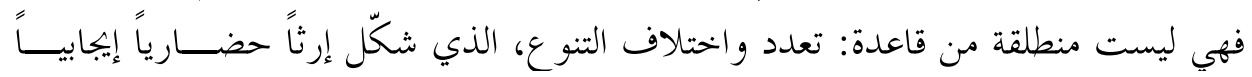

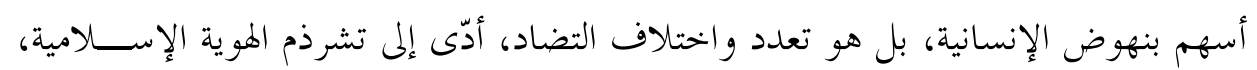




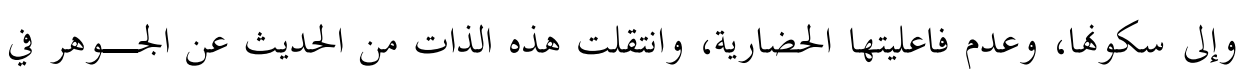

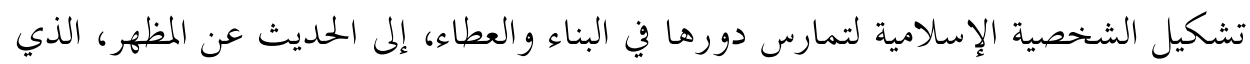
غدا عاملاً في التعبير عن هوية المسلم. وبناء عليه فإن حديثنا عن إقبال هو حديث متجدد عن قدرة العقل المسلم في تحديــــ

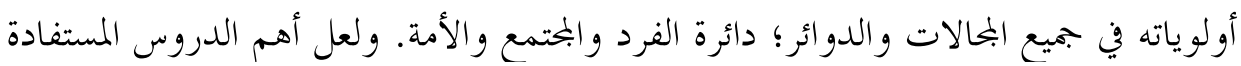
من بحربة إقبال نوردها بشكل مقتضب التهات فيما يأتي: الدرس الأول: "يا بين اقرَأ القرآن و كأنه أُنزل عليك"؛ لم تكن جهلة شاعرية مقصودة

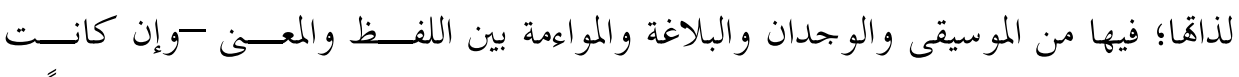

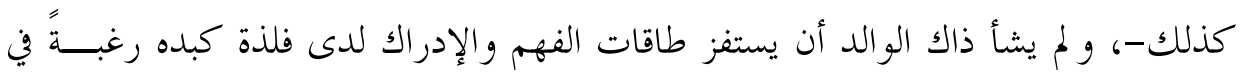

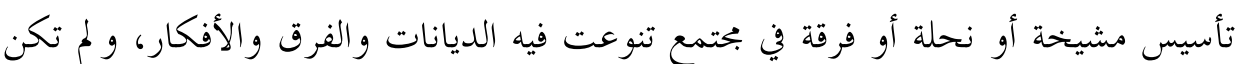

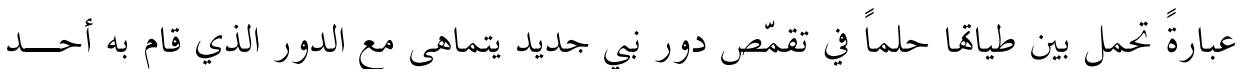

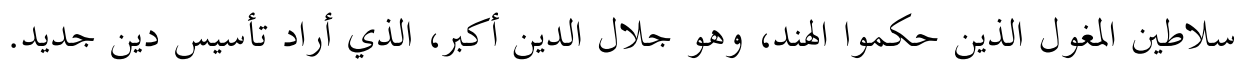
بل هو خطاب بتديدي في فهم مقاصد القرآن، وهي جملة تحريضية لإعادة فهم الإسلام في

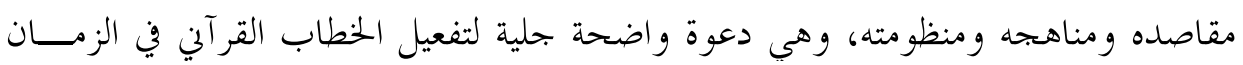

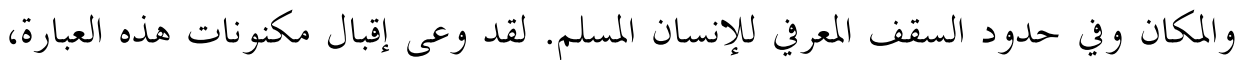

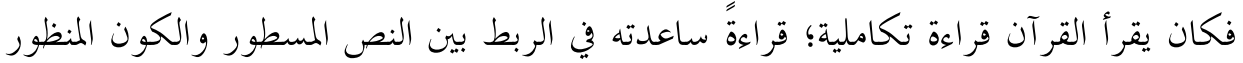

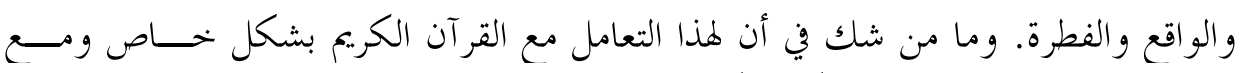

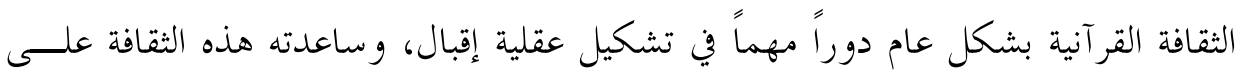

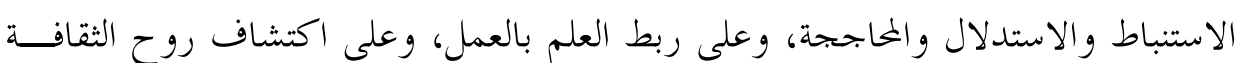

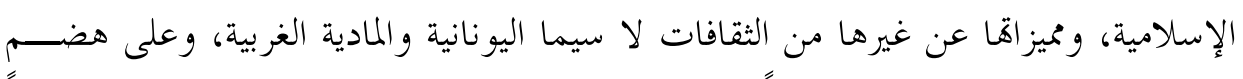

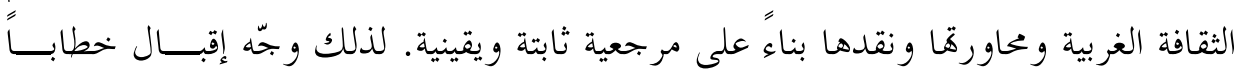

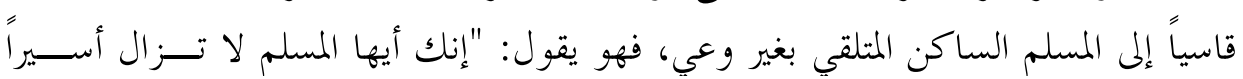

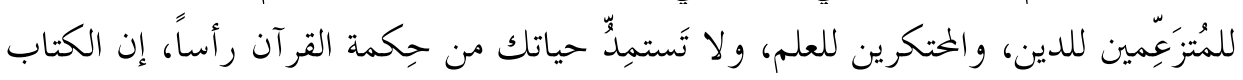

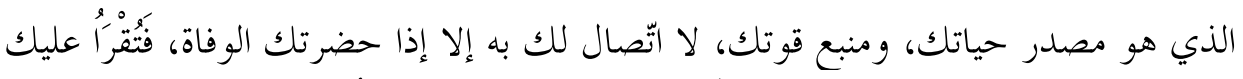

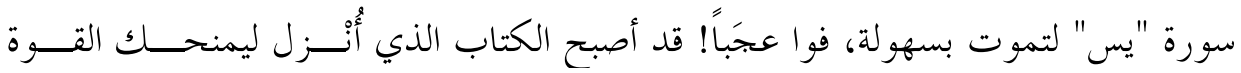

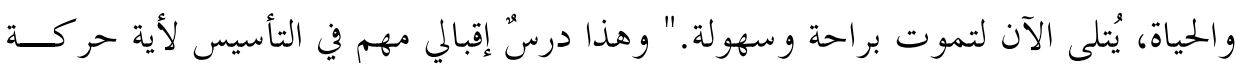

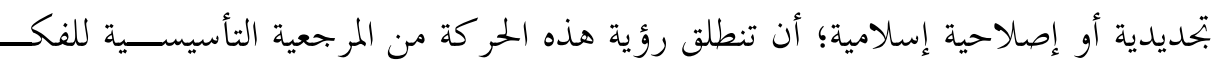


الإسلامي، المتمثلة في النص المهيمن والمؤسس وهو القرآن الكريم، وأن يستشعر المسلم بــأن المبان

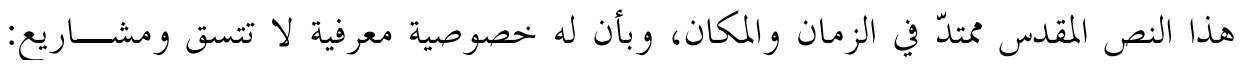

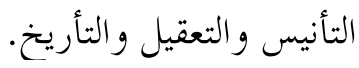

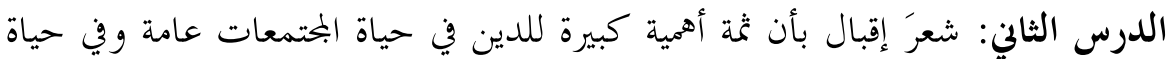

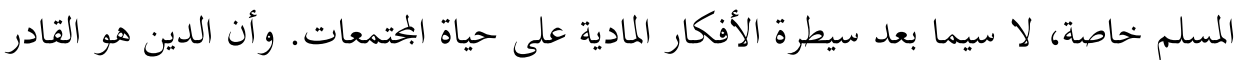

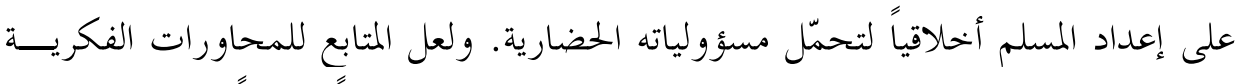

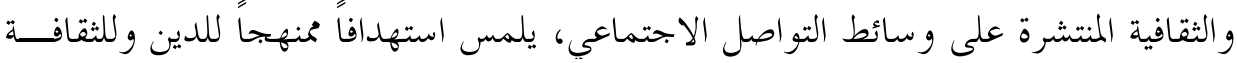

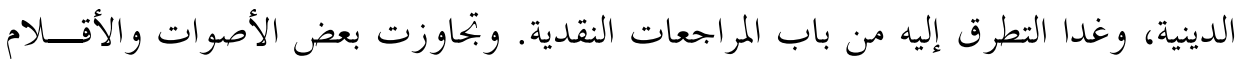

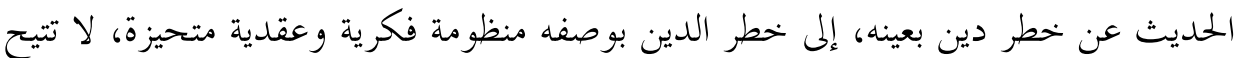

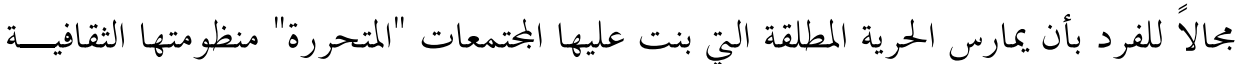

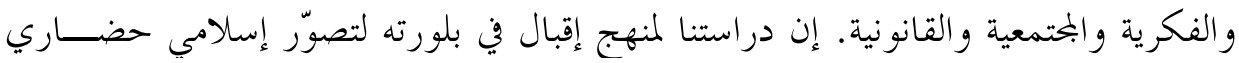

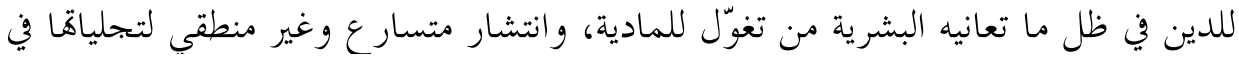

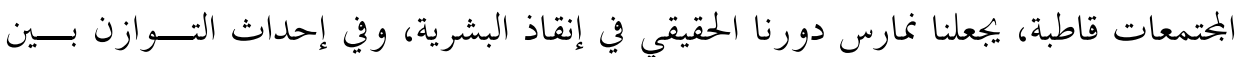

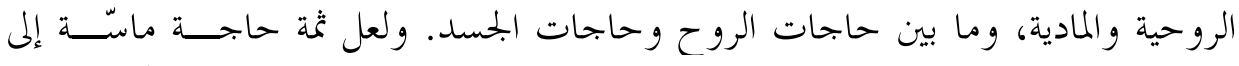

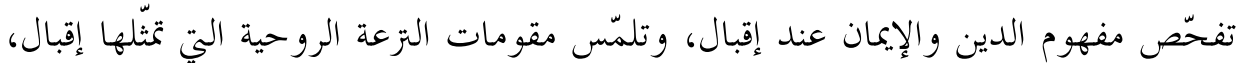

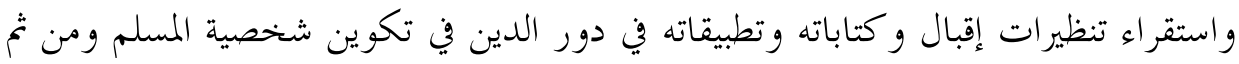

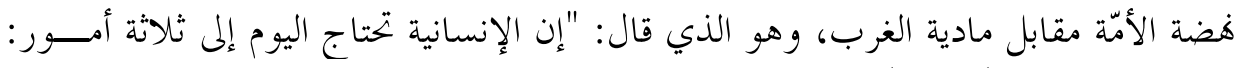

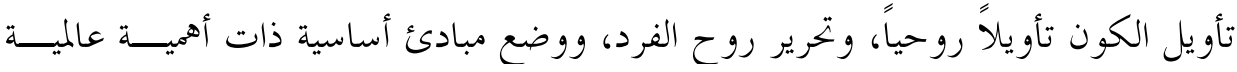

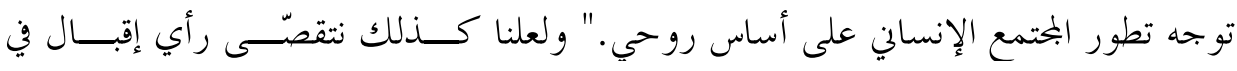

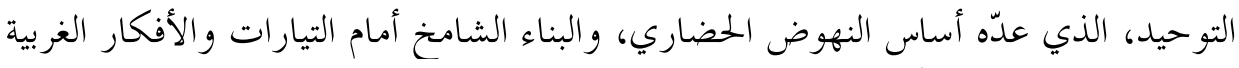

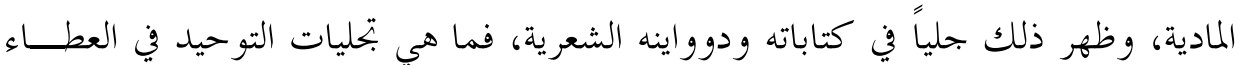

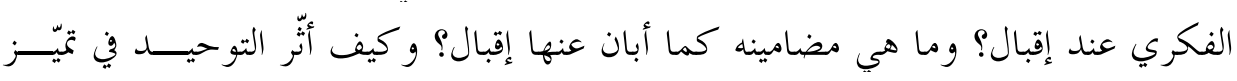
الشخصية الإسلامية، وإنحازات الحضارة الإسلامية؟ الفئه

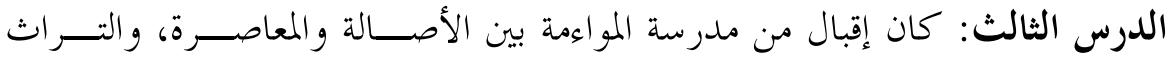

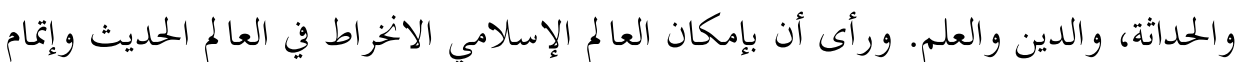

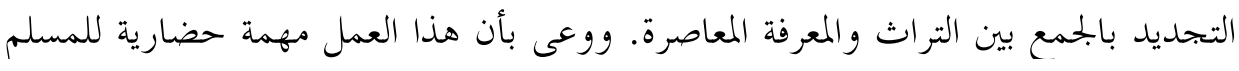

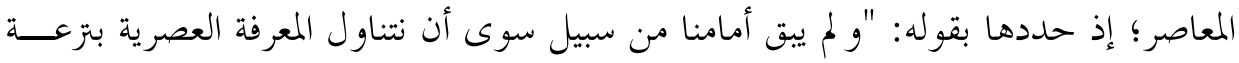


من الإجالال، وفي روح من الاستقلال، والبعد عن الهوى. وأن نقدّر تعاليم الإسلام في ضوء

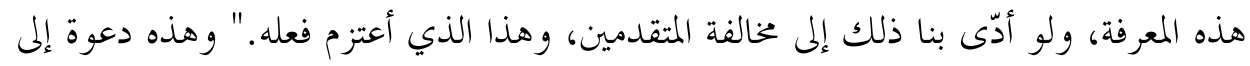

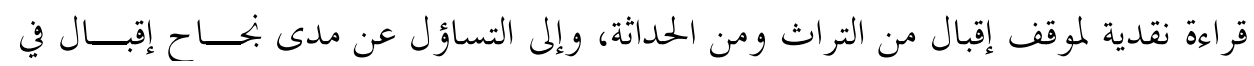

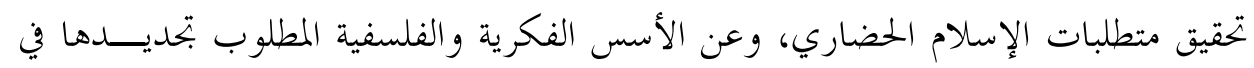

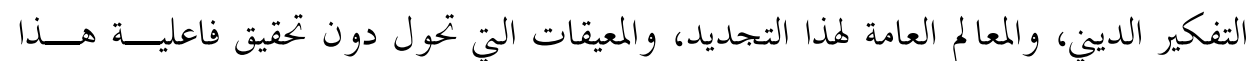
التجديد.

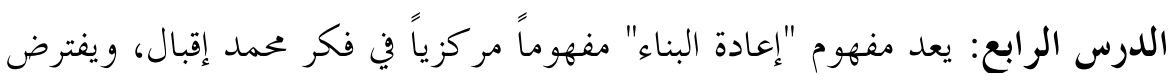

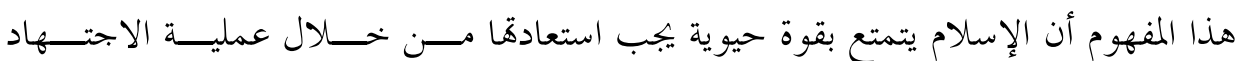

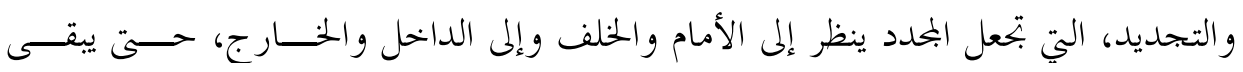

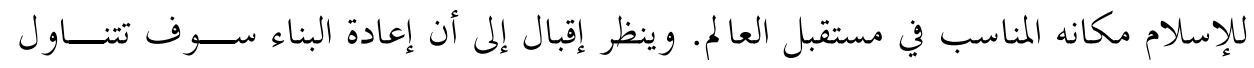

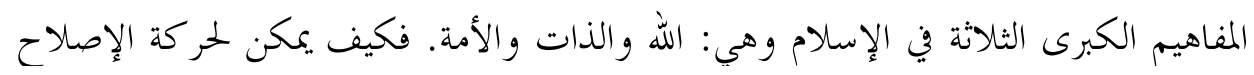

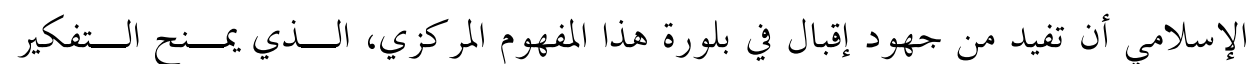

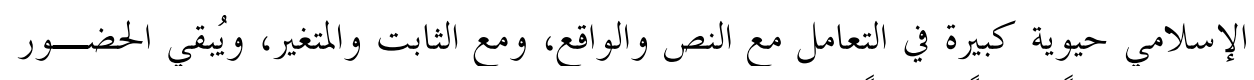

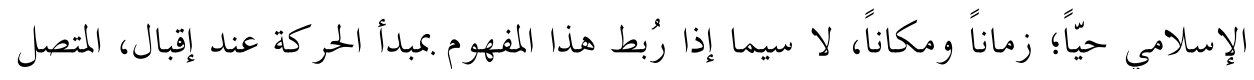

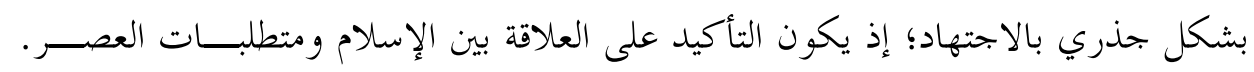

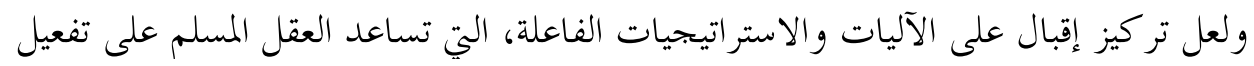

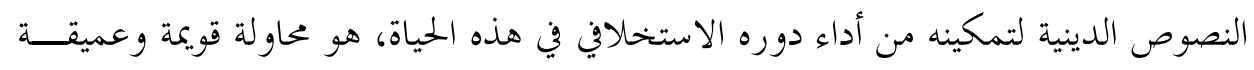

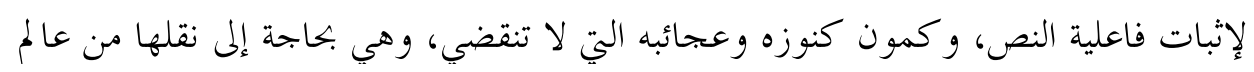

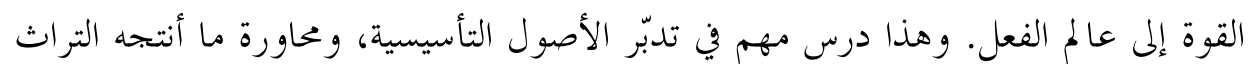

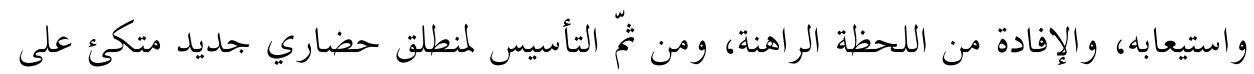

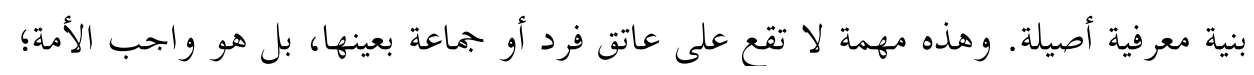

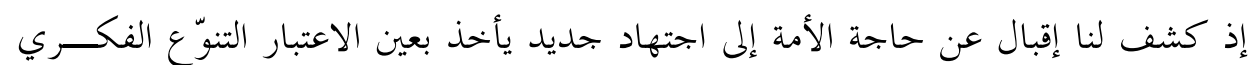

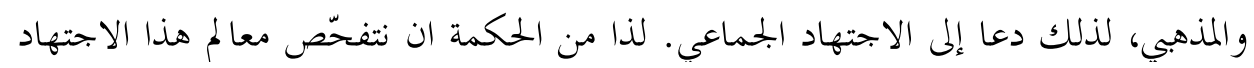
عند إقبال، وضرورته الحضارية في سياق الحديث عن الذات والمختلف، والفي ومرجعياته وأسسه.

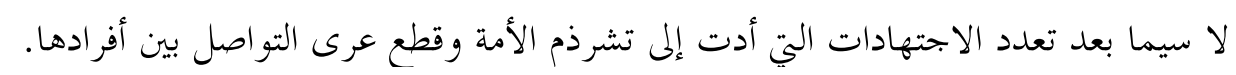

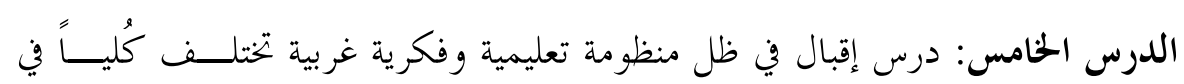
بنائها المعرفي عن النظام المعرفي الإسلامي، من حيث المصال في مندر والرؤية والأداة والغاية والبنية. 
وحاول إقبال في أطروحاته الجحامعية خاصة أن يبلور التصوّر الإسلامي للرؤية الكلية بحـــاه

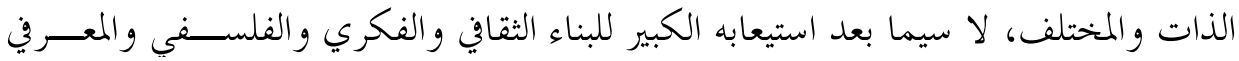

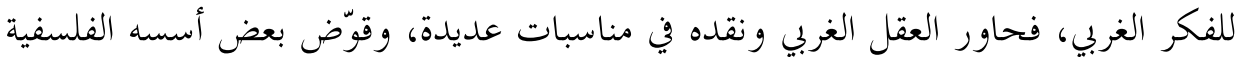

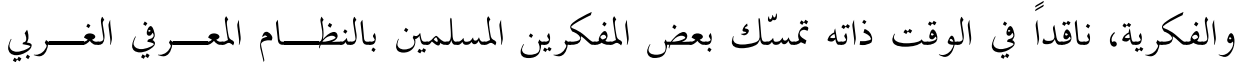

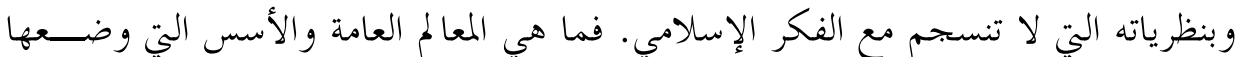

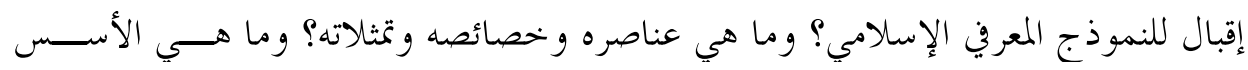

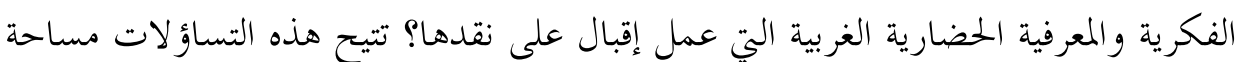

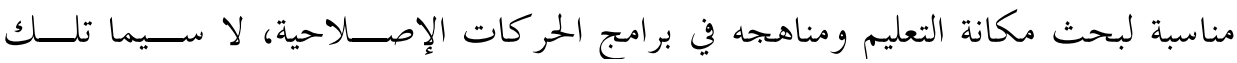

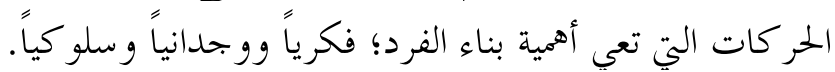

الدرس الحخامس: مثّل إقبال منهجاً فكرياً عملياً أسهم في تثبيت هوية المسلمين في شبه

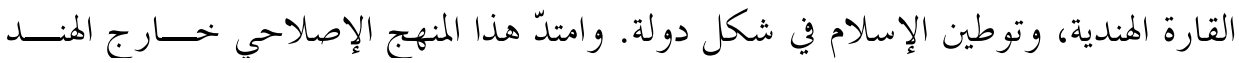

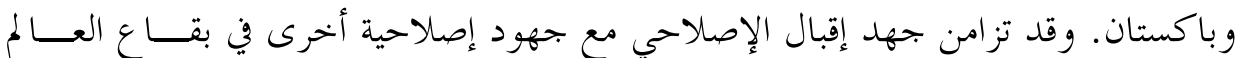

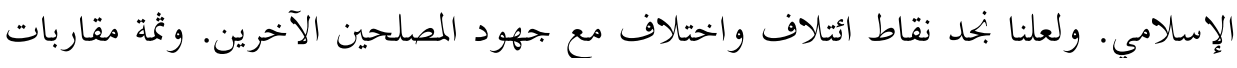

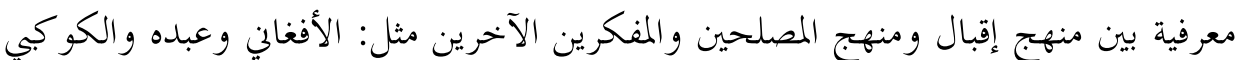

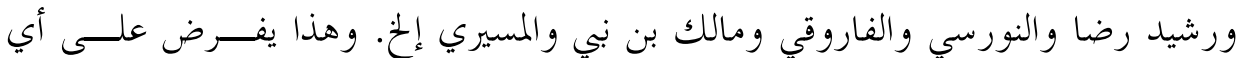

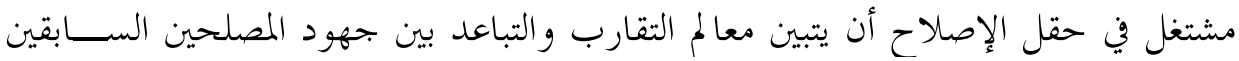

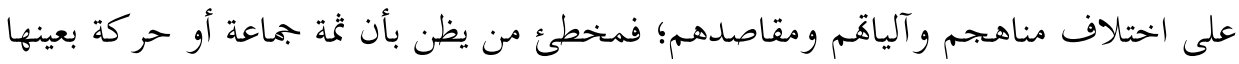

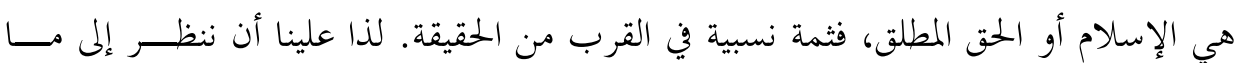

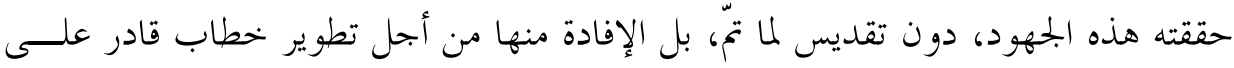

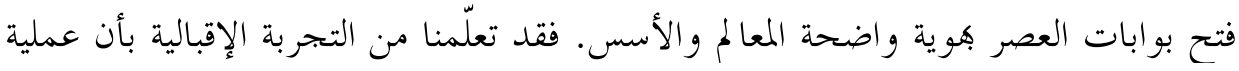

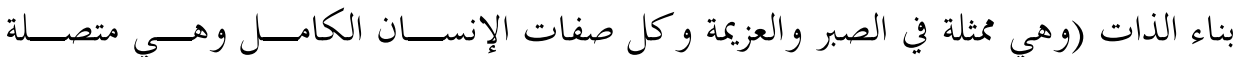

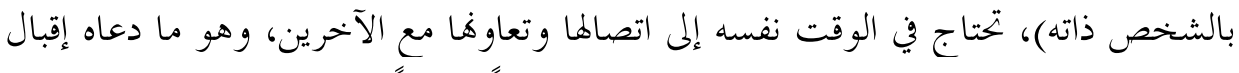

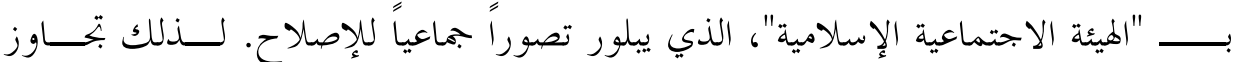

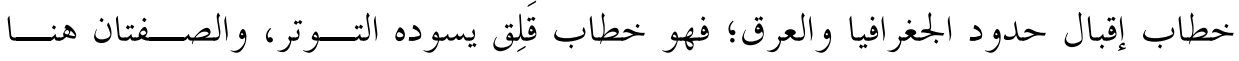

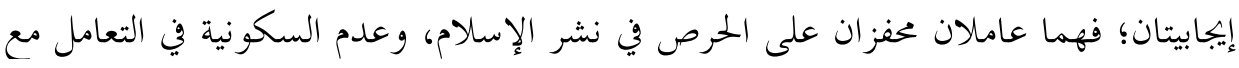
الأفكار القديمة و المستجدة. 


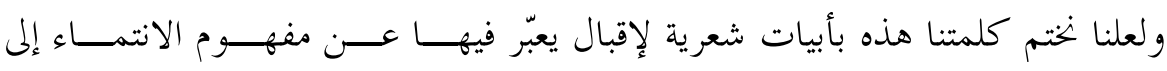

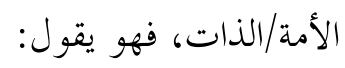

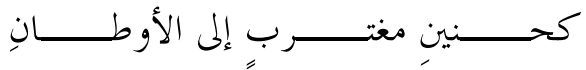

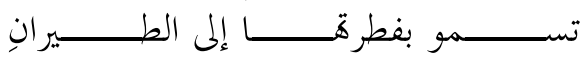

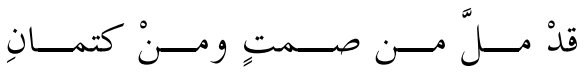

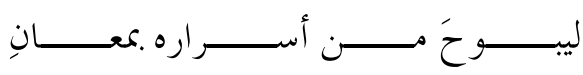

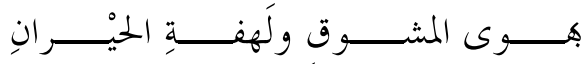

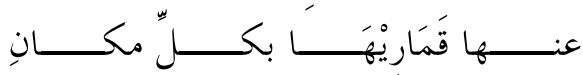

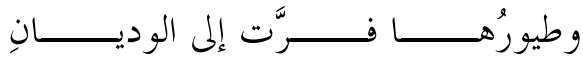

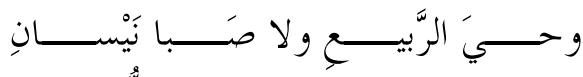

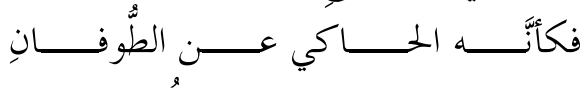

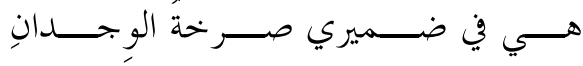

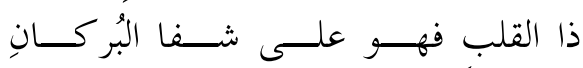

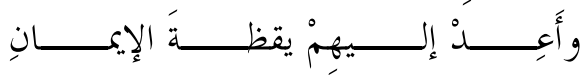

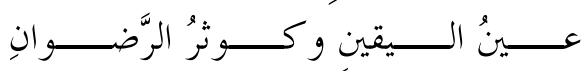

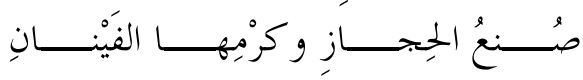

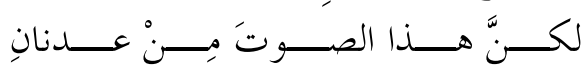

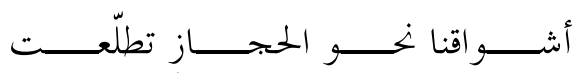

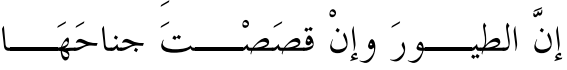

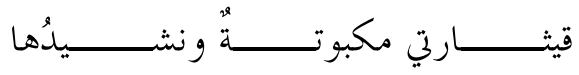

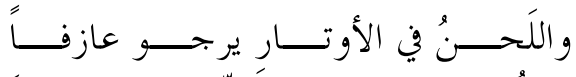

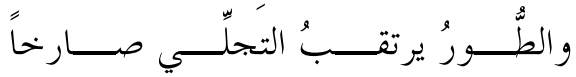

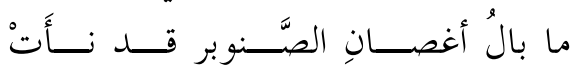

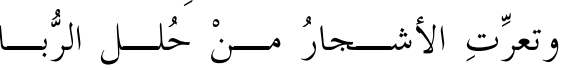

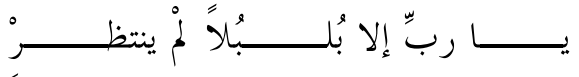

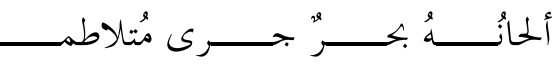

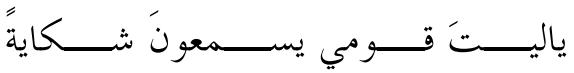

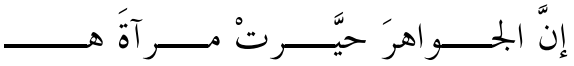

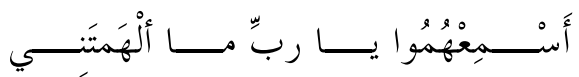

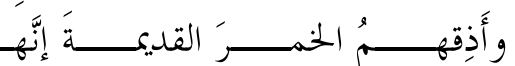

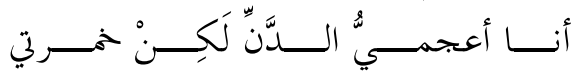

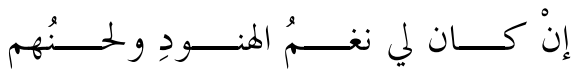

و يسرنا في بحلة إسلامية المعرفة: بحلة الفكر الإسلامى المعاصر أن نقدّم لقرائها ومتابعيها

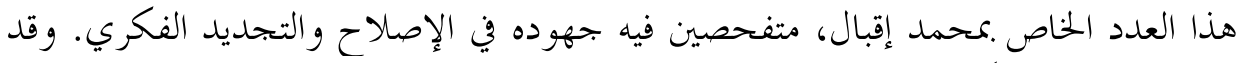

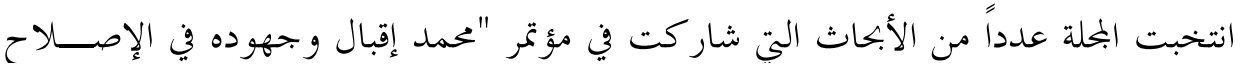

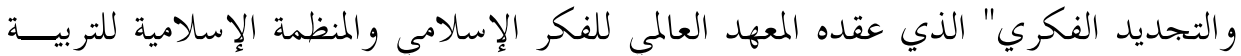

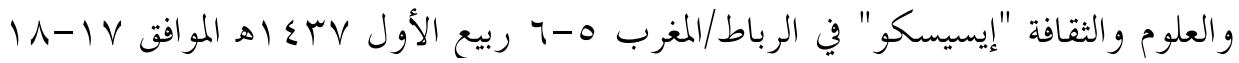

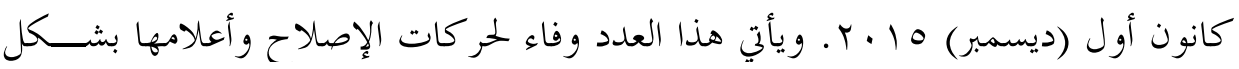

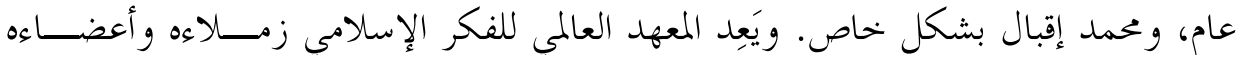

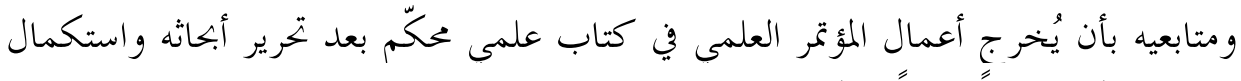
محاوره؛ ليكون زاداً علمياً للمكتبة العربية و الإسلامية. 